surface antigens (CD41, CD61) in children with immune thrombocytopenic purpura (ITP) have a diagnostic and pathogenesis role.

\section{ZINC DEFICIENCY IN LYMPHOMA AND LEUKEMIA}

doi:10.1136/archdischild-2012-302724.0774

Z Tahannejad Asadi, D Dayer. Ahvaz Jundishapur University of Medical Sciences (AJUMS), Para-Medical Faculty, Department of Medical Laboratory Sciences, Ahvaz, Iran

Background With regard to antioxidant role of zinc in body, zinc deficiency may be considered as one of the carcinogenic agents. Thus the determination of zinc deficiency percent in patients who are suffered from different types of cancers is useful to determine the dose of zinc supplementation which is used to such patients. In this study we evaluated the percent of zinc deficiency in different types of leukemic and lymphoma patients in comparison with normal subjects.

Methods Case population was considered of 50 patients who suffered from different types of leukemia (ALL, AML) and lymphoma. Our control was considered of 50 normal subjects with the same range of age (10-30 year). Atomic Absorption was used in order to determine zinc concentration.

Results Zinc deficiency percent was $73.3 \%$ in ALL and $54.5 \%$ in AML leukemic patients. $42.9 \%$ of lymphoma patients were zinc deficient. However zinc deficiency was seen in $16.7 \%$ of normal subjects too. It was not significant relation between the age and zinc concentration in both lymphoma and leukemic patients $(p=0.39$ and $p=0.34$ ). In patients and normal groups mean zinc concentration in men was not statistically different from women $(p=0.99$, $\mathrm{p}=0.41$ ).

Conclusion Results obtained in this study indicate that zinc deficiency is a serious difficult in our country. Because of $16.7 \%$ zinc deficiency in normal subjects, zinc supplementation is recommended for all normal and abnormal subjects. However the dose of zinc supplementation must be determined carefully in regard to some factors such as age, sex and different abnormalities.

\section{MYOCARDIAL PERFORMANCE INDEX (TEI INDEX) IN PRETERM NEONATES WITHOUT BPD}

doi:10.1136/archdischild-2012-302724.0775

'R Bokiniec, ${ }^{2} \mathrm{P}$ Własienko, ${ }^{2} \mathrm{~J}$ Szymkiewicz-Dangel, 'MK Kornacka. 'Neonatal and Intensive Care Department; ${ }^{2}$ Perinatal Cardiology Unit, Medical University of Warsaw, Warsaw, Poland

Background To define age-related changes in left (LV) and right (RV) ventricular function by using myocardial performance index (Tei Index) in preterm neonates.

Materials and Methods 18 newborn infants were selected from preterm neonates with the gestational age of 24-32 weeks, mean birth weight $917.5 \mathrm{~g}$ (min. 520, max. $1920 \mathrm{~g}$ ). The Tei Index is a Doppler-derived myocardial performance tool which can be used to evaluate the systolic and diastolic function. The first measurement was taken as soon as possible after birth, the second one was taken on day 3 of life, the third one at the 40 th wk post-conceptional age (pca).

Results The higher Tei index was obtained in the RV (mean value - 0.39; SD +/-0.15) then the LV (mean value - 0.36; SD +/-0.10) in the first day of life. In the LV the Tei index was constant during the neonatal period and at $40 \mathrm{wks}$ pca (from mean value 0.36 -day 1 , 0.35 day 3 and at 40 wks pca.), and we observed the conversion in the RV between the first and the third day of life and at $40 \mathrm{wks}$ pca (mean value 0.39 - day 1 to 0.30 -day 3 and to 0.28 at 40 wks pca).

Conclusion The higher mean value of the Tei index in the RV might be reflecting the "persistent" fetal status of this ventricle in the first day of life. Although constant value of the Tei index in the
LV reflect the degree of neonatal myocardial immaturity. GrantMNiSW No. 407414336.

\section{CHANGING OF JONS CRITERIA WITH LESS OR MORE CRITERIA?}

doi:10.1136/archdischild-2012-302724.0776

H Ghaffari. Medical University of Iran, Tehran, Iran

The more patient come in emergency department with tachcardia and one major criteria with others nonspecific labratory data has rheumatic fever and some with 2 major criteria can not explain totally RF so its looks like the jons criteria found some variatin and nowadays cannot explain RF totally and may be some variation an mutation in streptococcus kinds that explains it

\section{A COMPARISON OF DIFFERENT METHODS OF TEMPERATURE MEASUREMENT BY MOTHERS AND PHYSICIANS IN HEALTHY NEWBORNS}

doi:10.1136/archdischild-2012-302724.0777

${ }^{1} \mathrm{MY}$ Oncel, ${ }^{2} \mathrm{KS}$ Tekgunduz, 'R Ozdemir, 'E Calisici, ${ }^{3} \mathrm{~S}$ Karahan, ${ }^{10}$ Erdeve, ${ }^{1} \mathrm{SS}$ Oguz, 1,4U Dilmen. 'Neonatology, Zekai Tahir Burak Maternity Teaching Hospital, Ankara; ${ }^{2}$ Neonatology, Ataturk University, Faculty of Medicine, Erzurum; ${ }^{3}$ Biostatistics, Hacettepe University, Faculty of Medicine; ${ }^{4}$ Pediatrics, Yıldırım Beyazıt University, Faculty of Medicine, Ankara, Turkey

Backgraund and aim: The aim of this study was to compare the accuracy of digital axillary thermometer (DAT), rectal glass mercury thermometer (RGMT) and infrared forehead skin thermometer (IFST) measurements made by mothers and physicians in healthy newborns.

Methods The body temperature measurements of 120 healthy newborns were made on their 2nd day of life using DAT, RGMT and IFST, first by mothers followed by a designated physician. Correlation analysis was performed for the measurements obtained by mothers and the physician. The presence of a former child or children at home, the educational level of the mother and maternal age were also recorded.

Results No correlation was observed between the measurements made by mothers and the physician using RGMT $\left(\mathrm{R}^{2}=0.096\right)$. The temperatures measured by mothers and the physician showed a significant correlation when a DAT and IFST were used $\left(R^{2}=0.923\right.$, $\mathrm{p}<0.001 ; \mathrm{R}^{2}=0.916, \mathrm{p}<0.001$, respectively).

Conclusions Difficulty of use and interpretation make RGMTs less practical than DATs and IFST for use by mothers. Measurements with an IFST are obtained from a newborn's forehead in a shorter length of time compared to DATs, which makes it a more practical option.

\section{HEMODYNAMIC SUPPLY OF THE AFFECTED OF NEPHROBLASTOMA KIDNEY}

doi:10.1136/archdischild-2012-302724.0778

1,2| Begun. 'Belarusian Research Center for Pediatric Oncology, Hematology and Immunology; ${ }^{2}$ Belarusian Medical Academy of Post-Graduate Education, Minsk, Belarus

Purpose To study of the hemodynamic supply for the affected of nephroblastoma kidney and compare it with the contralateral kidney.

Patients and methods: We analyzed the data obtained by Doppler studies of blood flow in the main renal arteries in 23 children aged 2.5(1.3-3.0) years of both sexes with a solid tumor of mostly in the upper pole one of his kidneys. Volume of the tumor in each case was less than $600 \mathrm{~cm}^{3}$. All of them had a diagnosis of monolateral nephroblastoma. 
Results It is established that the nephroblastoma increases blood flow to the main artery of the affected kidney compared with the contralateral ( $p=0,00003$ ). According to our data the volume of the affected organ with nephroblastoma correlated with blood flow in his main artery $(r=0.45 ; \mathrm{p}<0.05)$. Such dependence can reflect the pathological circulation of the affected kidney. It also reflects the need to change the absolute amount of blood flow in tumor growth. At the same time in a healthy kidney specific blood flow much higher than that of the affected $(p=0,00001)$. Indices of relative blood flow affected and contralateral kidneys were 1.32 (1.04-2.13) $\mathrm{ml} / \mathrm{cm}^{3} / \mathrm{min}$ and $5.46(3.73-6.78) \mathrm{ml} / \mathrm{cm}^{3} / \mathrm{min}$, respectively.

Conclusions Thus, the hemodynamic characteristics the affected of nephroblastoma kidney were studied. Specific blood flow of affected organ with a continuous functional activity is significantly less with respect to the contralateral (not affected). These data may prove useful in the development of differential diagnostic criteria for distinguishing nephroblastoma and adrenal neuroblastoma at the stage of diagnosis.

\section{BLOOD PRESSURE AND HEART RATE DO NOT REFLECT CARDIAC OUTPUT IN CRITICALLY ILL CHILDREN}

doi:10.1136/archdischild-2012-302724.0779

'A Nusmeier, ${ }^{2} \mathrm{PJ}$ Gooskens, 'JG van der Hoeven, ' IJ Lemson. 'Intensive Care, Radboud University Nijmegen Medical Center, Nijmegen; ${ }^{2} T e c h n i c a l$ Medicine, University of Twente, Enschede, The Netherlands

Introduction Treatment to support the circulatory state is often based on the interpretation of clinical parameters while advanced hemodynamic monitoring is not always available or applied in children. Cardiac output(CO) measurement using the transpulmonary thermodilution(TPTD) technique is the gold standard in pediatric patients. We studied the predictive value of clinical parameters of (changes in) $\mathrm{CO}$ by comparing the blood pressure and heart rate values with intermittent $\mathrm{CO}_{\text {TPTD }}$ measurements.

Methods A retrospective observational study was performed in a heterogenic critically ill pediatric patient population. Doses of inotropics, if administered, was registered to study their influence on trend monitoring. $\mathrm{CO}$ was compared with heart rate(HR) and mean arterial blood pressure(MAP) one minute before every CO measurement. The results were analyzed using correlation and linear regression statistics.

Results 216 CO measurements in 20 patients were analyzed. Median age was 1.7 (range 0.3-5.2) years and median body weight 8.8 (range $3.8-18$ ) kg. The median CO was 1.88 (range 0.61-5.64)1/ min. The correlation coefficient (Spearman's rho) between the CO and HR and MAP was $-0.08(p<0.24)$ resp. 0.31 $(p<0.0001)$. Linear regression analysis of $\mathrm{CO}$ and both $\mathrm{HR}$ and $\mathrm{MAP}$ and the influence of inotropics on the relation of changes in $\mathrm{CO}$ and changes in $\mathrm{HR}$ and MAP are shown in table 1.

Conclusions Heart rate and blood pressure are unreliable in predicting cardiac output in critically ill children. The use of inotropics seems to increase the correlation between changes in HR and BP and changes in $\mathrm{CO}$.

Abstract 779 Table 1 Linear regression analysis

\begin{tabular}{|c|c|c|c|c|}
\hline dopendent varibblo & Indopendentyziallas & sumplecine. & $\pi$ & cienilisance lovel \\
\hline co (all) & HR, MAP & 215 & 0.29 & $<0,001$ \\
\hline Aco (alli) & $\triangle(H R, M A D)$ & 215 & 0.37 & $<0.001$ \\
\hline$\triangle C O(+$ inotropics) & $\triangle(M, D, M A P)$ & 119 & 0.45 & 00.001 \\
\hline$\Delta C O$ - inotropiss) & $\triangle(H E, M A D)$ & 97. & 0.27 & $<0.031$ \\
\hline
\end{tabular}
NEVUS SYNDROME IN A CHILD

doi:10.1136/archdischild-2012-302724.0780

F Alsohime. Pediatric Nephrology, Hopital Femme Mere Enfant, Lyon, France
Epidermal nevus syndrome is a rare congenital sporadic neuroectodermic disorder, characterized by the presence of epidermal nevi in association with various developmental abnormalities of the skin, eyes, nervous, skeletal, cardiovascular and urogenital systems. We describe a 5-year-old boy with conjunctival lipodermoid, cervical and facial sebaceous nevi who presented at 3 years of age with hypertension due to bilateral renal artery stenosis together with multiple vascular anomalies (aorta, celiac trunk, superior mesenteric artery) as shown by magnetic resonance angiography. Systemic arterial hypertension was difficult to control despite combined anti-hypertensive drugs and the surgical repair of the aortic coarctation.

\section{SEEKING FOR DEFINITIONS OF POOR PERFUSION STATES (PPS) IN LOW BIRTH WEIGHT INFANTS (LBWI) (PART II)}

doi:10.1136/archdischild-2012-302724.0781

'MC Bravo, 'P López-Ortego, 'L Sánchez, ${ }^{2} \mathrm{~J}$ Riera, ${ }^{1} \mathrm{~F}$ Cabañas, ${ }^{3} \mathrm{E}$ Pérez-Fernández, 1J Quero, 'A Pellicer. 'La Paz University Hospital, Department of Neonatology; ${ }^{2 B i o-}$ Engineer and Nanotechnology Department, Polytechnic University of Madrid; ${ }^{3}$ Division of Statistics, La Paz University Hospital, Madrid, Spain

Background and Aims No validated scoring system to diagnose PPS in LBWI is available. Echocardiography (Echo)-derived low superior vena cava flow (SVCF) is a biomarker of PPS in this population as associates adverse outcome. We examined the ability of clinical surrogates of low systemic blood flow to indicate PPS as defined by low SVCF.

Methods One hundred LBWI [27.4 (2) wks; 1014 (316) g] who reached disease score below threshold, underwent early $(<12 \mathrm{~h})$ and serial Echo scans during the first $96 \mathrm{hs}$ after birth. Mean blood pressure $(\mathrm{MBP})$, lactate, base excess $(\mathrm{BE})$, core-to- peripheral temperature gap (DT) and diuresis were registered at the time of Echo assessment. N-terminal probrain natriuretic peptide (NT-proBNP) and troponine were measured within $24 \mathrm{~h}$ and at postnatal day 4 .

Results No association between SVCF and MBP, lactate, BE, DT, diuresis or troponine was found. NT-proBNP was inversely related to SVCF ( $p=0.006)$. Low SVCF $(<41 \mathrm{~mL} / \mathrm{k} / \mathrm{min})$ was present in the first Echo (4.2h) in 27 patients. At that time, the sensitivity and specificity of the clinical parameters to predict low SVCF was, respectively: lactate $>4.5 \mathrm{mmol} / \mathrm{L}(22.2 \%$; 89.4\%); BE <-9 $(6.9 \%$; $92.9 \%) ; \mathrm{MBP}<30 \mathrm{mmHg}$ (25\%; 64.6\%); DT (15\%; 78.8\%). Combination of lactate and BE did not improve accuracy.

Conclusions PPS is a common condition early after birth in the sick LBWI. The role of Echo-derived systemic blood flow assessment to identify PPS cannot be replaced by clinical assessment solely.

Disclaimer Supported by the Spanish Health Ministry and the SAMID network.

\section{NEW DILUTION METHOD FOR OP/OS MEASUREMENT IN PATIENTS WITH SINGLE VENTRICLE (SV) ANATOMY}

doi:10.1136/archdischild-2012-302724.0782

N Krivitski, V Kislukhin, N Thuramalla, A Kriksunov. Transonic Systems Inc., Ithaca, NY, USA

Background and Aims Major challenge for treatment of Hypoplastic left heart syndrome by Norwood procedure is in achieving the adequate $\mathrm{ap} / \mathrm{Qs}$ value. The absence of routine method of assessing the Op/Os value can lead to hypoxia, brain injury, for $\mathrm{Op} / \mathrm{Q} s<<$ 1 or to insufficient tissue perfusion and lung edema for $a_{p} / Q_{s}>>1$. The aim of the study was to develop routine method for $\mathrm{Op} / \mathrm{Os}$ assessment for PICU and NICU patients.

Method development: A mathematical model of indicator movement for SV anatomy was developed. After intravenous injection and mixing in SV the first portion of the indicator enters systemic 